\title{
Study of Risk Factor for Congenital Heart Diseases in Children at Rural Hospital of Central India
}

\author{
Taksande AM1', Vilhekar $\mathrm{K}^{2}$ \\ ${ }^{1}$ Dr. Amar M Taksande, MBBS, MD, FIAE, Fellowship \\ in Paediatric Cardiology, Professor, Department \\ Paediatrics, Jawaharlal Nehru Medical College, Swangi \\ Meghe, Wardha, Maharastra, India, ${ }^{2} \mathrm{Dr}$. Krishna \\ Vilhekar, MBBS, DCH, MD, Professor and Head, \\ Department of Paediatrics, Mahatma Gandhi Institute \\ of Medical Sciences, Sewagram, Wardha, Maharastra, \\ India.
}

\section{Introduction}

Cas ongenital Heart Disease (CHD) is defined as a gross structural abnormality of the heart or intrathoracic great vessels that is actually or potentially of functional significance. It is the most common congenital problem that accounts for up to $25 \%$ of all congenital malformations that present in the neonatal period $^{1}$. The etiology of CHD is largely unknown and so prevention is almost impossible. A multifactorial inheritance is gaining ground which include genetics and environmental interaction in $90 \%$ and solely of genetic origin in $8 \%$ (chromosomal in $5 \%$ and single mutant gene $3 \%)^{2}$. CHD may present in any age group from neonatal age to adolescent age group and it may present with or without cyanosis, rapid breathing, perspiration, some with congestive cardiac failure, cyanotic spells, while some children may be asymptomatic but with a cardiac murmur detected during examination for any other illness ${ }^{3}$. There are certain risk factors which are responsible for congenital heart disease therefore this study was conducted to determine the risk factors for the development of congenital heart diseases in children at rural hospital.

\section{Materials and Methods}

This study was conducted in Department of Paediatrics, Mahatma Gandhi Institute of Medical College, Sevagram over a period of three year from March 2004 to April 2007. All the children with clinical suspicion of CHD were evaluated with history and

\begin{abstract}
Introduction: Congenital heart disease is the most common congenital problem that accounts for up to $25 \%$ of all congenital malformations. Hence this study was aimed at improving the knowledge related to risk factors associated with CHD in a rural Indian scenario. It was a hospital- based case control study. Materials and Methods: The children up to twelve year of age with clinical suspicion of CHD were subjected to chest $\mathrm{x}$-ray and electrocardiography, and final diagnosis was confirmed by echocardiography $(n=209)$ as cases. The control group $(n=418)$ were randomly selected from children without CHD who were admitted during the same period. The etiological factors like environmental, infections, drugs, and maternal factors were analyzed by using EPI 6 version. Results: In cases group, 56\% were male and $44 \%$ female children. $82 \%$ cases presented at age of less than 5 years and $18 \%$ after 5 year. Exposure to smoking (OR=10.45), tobacco intake by mother $(\mathrm{OR}=8.28)$ and family history of $\mathrm{CHD}$ $(O R=7.21)$ were the significant risk factor present in cases. Conclusion: The risk factors for $\mathrm{CHD}$ child identified were exposure to smoking and tobacco intake by mother, family history of $\mathrm{CHD}$, antenatal infection in $1^{\text {st }}$ trimester and history of diabetic mother.
\end{abstract}

Key words: Congenital heart disease, Etiology, Acyanotic, Cyanotic, Risk factor

clinical examination. They were initially investigated by performing complete blood cell count, chest x-ray and electrocardiography and final diagnosis was confirmed by echocardiography. The detailed history was taken in the congenital heart disease (cases=209) regarding the history of consanguinity and family history of congenital malformation. Antenatal history regarding drug intake, tobacco intake, alcohol intake, exposure to smoking, number of previous abortions, or history of diabetes

\author{
Address for correspondence \\ Dr. Amar M Taksande \\ Department of Paediatrics \\ Jawaharlal Nehru Medical College, \\ Sawangi Meghe, Wardha, Maharashtra - 442102. India. \\ E-mail: amar.taksande@gmail.com
}

\section{How to cite this article?}

Taksande AM, Vilhekar K. Study of Risk Factor for Congenital Heart Diseases in Children at Rural Hospital of Central India. J Nepal Paediatr Soc 2013;33(2):121-124. 
were inquired. The control group $(n=418)$ were randomly selected from children without congenital heart disease who were admitted during the same period. The child with acquired heart disease was excluded from the study. The statistical EPI 6 version was used and calculated the odds ratio (OR) to evaluate the strength of association of risk factors.

\section{Results}

Total 11,748 admissions occured in the paediatric wards during three year period. There were 209 (1.77\%) children with CHD of total admissions. $117(56 \%)$ cases were males and 92 (44\%) females. Male to female ratio was $1.25: 1$. Approximately $70 \%$ children were having acyanotic CHD. 104 (49.76\%) cases were presented in the first year of life, $68(32.53 \%)$ in 1 to 5 year and $37(17.70 \%)$ cases after 5 year of life. Table 1 shows the distribution of risk factor according to type of congenital heart diseases. In $92 \%$ cases, symptom started in infancy. The commonest symptoms were repeated chest infection, breathlessness, palpitation, failure to thrive, and cyanosis. 13 (6.22\%) cases had extracardiac malformation mainly limb and renal abnormality. Table 2 shows the distribution of risk factor in cases and controls group. Exposure to smoking ( $O R=10.45$, 95\% Cl 2.13 ; 69.71), tobacco intake by mother (OR=8.28, $95 \% \mathrm{Cl} 1.62 ; 56.93)$ and family history of congenital heart disease $(\mathrm{OR}=7.21,95 \% \mathrm{Cl} 1.48 ; 35.01)$ were the significant risk factor present in cases groups as compared to the control groups.

Table 1: Distribution of risk factor according to type of congenital heart disease.

\begin{tabular}{|c|c|c|c|c|c|c|c|c|c|c|c|}
\hline \multirow[t]{2}{*}{ Type of CHDs } & \multirow[t]{2}{*}{ FHC } & \multirow[t]{2}{*}{ HOC } & \multicolumn{4}{|c|}{ ANC Infection (1st trimester) } & \multirow[t]{2}{*}{ HODM } & \multirow[t]{2}{*}{ DRG } & \multirow[t]{2}{*}{ ALC } & \multirow[t]{2}{*}{ TOB } & \multirow[t]{2}{*}{ Smoke } \\
\hline & & & Rub & Var & Hep & CMV & & & & & \\
\hline \multicolumn{12}{|l|}{ 1. Acyanotic CHD } \\
\hline ASD & 1 & 6 & 1 & 0 & 0 & 0 & 3 & 0 & 0 & 2 & 2 \\
\hline VSD & 3 & 7 & 1 & 0 & 0 & 0 & 2 & 2 & 1 & 2 & 2 \\
\hline PDA & 1 & 5 & 3 & 1 & 0 & 0 & 8 & 0 & 0 & 0 & 1 \\
\hline ECD & 0 & 2 & 0 & 1 & 0 & 0 & 0 & 1 & 0 & 0 & 1 \\
\hline Mixed & 1 & 3 & 0 & 0 & 0 & 0 & 0 & 0 & 0 & 0 & 0 \\
\hline \multicolumn{12}{|l|}{ 2.Obstructive } \\
\hline PS & 1 & 1 & 0 & 0 & 1 & 0 & 0 & 0 & 0 & 1 & 0 \\
\hline AS & 0 & 0 & 0 & 0 & 0 & 0 & 0 & 0 & 0 & 0 & 1 \\
\hline COA & 0 & 0 & 0 & 0 & 0 & 0 & 0 & 1 & 0 & 0 & 0 \\
\hline \multicolumn{12}{|l|}{ 3. Cyanotic CHD } \\
\hline TGA & 0 & 1 & 0 & 0 & 0 & 0 & 0 & 0 & 0 & 0 & 1 \\
\hline TOF & 0 & 3 & 0 & 0 & 0 & 1 & 1 & 1 & 0 & 2 & 0 \\
\hline Ebstein's anomaly & 0 & 0 & 0 & 0 & 0 & 0 & 0 & 0 & 0 & 0 & 1 \\
\hline TA & 0 & 0 & 0 & 0 & 0 & 0 & 0 & 0 & 0 & 0 & 0 \\
\hline PAPVC & 0 & 0 & 0 & 0 & 0 & 0 & 0 & 0 & 0 & 0 & 0 \\
\hline TAPVC & 0 & 1 & 0 & 0 & 0 & 0 & 0 & 0 & 0 & 0 & 0 \\
\hline Truncus Arteriosus & 0 & 0 & 0 & 0 & 0 & 0 & 0 & 0 & 0 & 0 & 1 \\
\hline Single Ventricle & 0 & 1 & 0 & 0 & 0 & 0 & 0 & 0 & 0 & 0 & 0 \\
\hline 4. Complex CHD & 0 & 3 & 0 & 0 & 0 & 0 & 0 & 0 & 0 & 1 & 0 \\
\hline Total Number (\%) & $\begin{array}{c}7 \\
(3.34)\end{array}$ & $\begin{array}{c}33 \\
(15.78)\end{array}$ & $\begin{array}{c}5 \\
(2.39)\end{array}$ & $\begin{array}{c}2 \\
(0.95)\end{array}$ & $\begin{array}{c}1 \\
(0.47)\end{array}$ & $\begin{array}{c}1 \\
(0.47 \%)\end{array}$ & $\begin{array}{c}14 \\
(6.69)\end{array}$ & $\begin{array}{c}5 \\
(2.39)\end{array}$ & $\begin{array}{c}1 \\
(0.47)\end{array}$ & $\begin{array}{c}8 \\
(3.82)\end{array}$ & $\begin{array}{c}10 \\
(4.78)\end{array}$ \\
\hline
\end{tabular}

FHC: family history of congenital heart disease, HOC: History of consanguinity, Rub: Rubella, Var: Varicella, Hep: Hepatitis, CMV: Cytomegalovirus, HODM: History of diabetic mother, DRU: Drug Intake, ALC: Alcohol intake, TOB: Tobacco intake, Smoke: Exposure to smoke 
Table 2: Distribution of risk factor in cases and controls.

\begin{tabular}{|l|c|c|c|}
\hline Risk Factors & Cases $\mathbf{( n = 2 0 9 )}$ & Control ( $\mathbf{n = 4 1 8 )}$ & OR (95\% CI ) \\
\hline History of consanguinity & 33 & 24 & $3.08(1.77 ; 5.36)$ \\
\hline Family history of CHD & 7 & 2 & $7.21(1.48 ; 35.01)$ \\
\hline Maternal History & \multicolumn{3}{|l|}{} \\
\hline Maternal h/o previous abortions and stillbirths & 11 & 7 & $3.26(1.15 ; 9.47)$ \\
\hline ANC Infection (1st trimester) & 9 & 4 & $4.66(1.42 ; 15.31)$ \\
\hline Diabetic mother & 14 & 5 & $5.93(2.11 ; 16.70)$ \\
\hline Drugintake & 5 & 2 & $5.10(0.98-25.50)$ \\
\hline Tobacco intake & 8 & 2 & $8.28(1.62 ; 56.93)$ \\
\hline Exposure to smoking & 10 & 2 & $10.45(2.13 ; 69.71)$ \\
\hline Mother Age (years) & & & \\
\hline$<20$ & 24 & 40 & $1.23(0.70 ; 2.09)$ \\
\hline $20-30$ & 153 & 346 & $0.57(0.38 ; 0.85)$ \\
\hline $30-35$ & 21 & 22 & $2.01(1.08 ; 3.75)$ \\
\hline$>35$ & 11 & 10 & $2.27(0.95 ; 5.43)$ \\
\hline
\end{tabular}

\section{Discussion}

Congenital heart diseases are leading cause of neonatal and infant mortality. During cardiogenesis various genetic and non-genetic environmental etiological factors are starting pathogenetic mechanism results in developing of $\mathrm{CHD}^{4}$. In $\sim 90 \%$ of the $\mathrm{CHD}$ cases, no identifiable cause detected and that can be attributed as multifactorial defects ${ }^{2}$. Hereditary factors may play a role since the incidence of $\mathrm{CHD}$ in sibling is significantly higher then in general population. If one child has the defect there is $2.5-5 \%$ chance that the second baby may have defect and $5-10 \%$ chance if second children have the defect ${ }^{5,6}$. The chances of the next child being affected by congenital cardiac malformation are more if the parents are consanguineous. In the present study, $15.78 \%$ were born of consanguineous marriages, mostly first cousin marriages. In our study, nearly $46 \%$ cases were born to primiparous mothers similar finding have been reported by Sugunabai ${ }^{7}$. Baltimore Washington Infant Study (BWIS) ${ }^{8}$ reported, two-fold excess of familial $\mathrm{CHD}$ in cases than controls whereas $3.34 \%$ cases had history of $\mathrm{CHD}$ in the family.

CHD are occurred more when the mother comes in contact with certain substances during the first few weeks of pregnancy, while the baby's heart is developing. The mother who had viral diseases like rubella and mumps in the first three months of pregnancy is more prone to develop multiple congenital anomalies including defects in hearts. Campbell's ${ }^{9}$ revealed that maternal rubella was responsible for $1-2 \%$ of malformation of the heart, Sugunabai ${ }^{7}$ reported $<2 \%$ whereas $2.3 \%$ in the present study. American Heart Association's 2006 ${ }^{10}$ concluded that women who smoke or are exposed to tobacco smoke early in their pregnancies are more likely to have children with certain types of $\mathrm{CHD}$. Begic $\mathrm{H}$ et $\mathrm{al}^{11}$ reported that $11.08 \%$ mothers were exposed to nicotine whereas in our study $3.82 \%$ had history of tobacco intake and $4.78 \%$ had exposure to smoking in mothers. Use of tobacco intake by mother during the $1^{\text {st }}$ trimester of pregnancy may acts as teratogens. In rural area of Maharashtra, $>50$ adolescents are used to take tobacco are found to be a significant risk factor for the development of congenital heart disease.

Women who have seizure disorders and need to take anti-convulsant medications may have a higher risk for having a child with congenital heart disease ${ }^{12}$. Preexisting maternal diabetes is associated with a fivefold increase in risk of cardiovascular malformations ${ }^{13}$. BWIS ${ }^{8}$ concluded that maternal diabetes is highly correlated with cyanotic CHD. Risk of CHD remains high for infant of women with poorly controlled elevated phenylalanine levels. No infant in our study had a history of maternal phenylketonuria. Maternal history of previous abortions and stillbirths were significant risk factors for $\mathrm{CHD}$ in offspring. Begic $\mathrm{H}$ et $\mathrm{al}^{11}$ reported that, more number of $\mathrm{CHD}$ cases $(83.14 \%)$ were present in children whose mothers were $20-35$ years old, while only $5.11 \%$ of mothers aged $>35$ year, same result was found in our study also. Major genetic defects such as chromosomal abnormalities were recognized as association with congenital heart disease with the identification of numerical excesses or deficiencies ${ }^{14}$. The chromosomal abnormality like trisomy 21 is mainly associated with endocardial cushion defect. We found that out of 10 cases of chromosomal abnormality, 8 cases had trisomy 21 defect. 


\section{Conclusion}

According to our knowledge, this was the first study carried out in rural hospital for assessing the risk factors for congenital heart disease in children at rural area of Maharashtra state. The risk factors for $\mathrm{CHD}$ child identified were intake of tobacco, exposure to smoking, family history of CHD, ANC infection in 1st trimester and history of child with diabetic mother. Still there are more elaborative studies required to assess various etiological factors associated with congenital heart disease.

Acknowledgements: None

Funding: None

Conflict of Interest: None

Permission from IRB: Yes

\section{References}

1. Mitchell SC, Korones SB, Berendes HW. Cogenital heart disease in 56,109 live births. Incidence and natural history. Circulation 1971;43:323-32.

2. Khalil A. Congenital heart disease. In: Essentials of Pediatrics Cardiology, IAP Cardiology chapter, New Delhi 2003;71-89.

3. Grabitz RG, Michel RJ, Collins-Nakai RL. Congenital heart disease: incidence in the first year of life. Am J Epidemiol 1988;128:381-388.

4. Frias JL. Genetic issues of congenital heart disease. In : Pediatric Cardiology, Edi. Gessner IH, Victrorica BE. Saunders, Philadelphia; 1993. p. 237-42.

5. Van Karnebeek CD, Hennekam RC. Associations between chromosomal anomalies and congenital heart defects. Am J Med Genet 1999;84:158-166.
6. Clark EB. Etiology of congenital cardiovascular malformations: epidemiology and genetics. In: Moss and Adams Heart Disease in Infant, Children and Adolescent. Edi. Allen HD,Gutgesell HP, Clark EB, Driscoll DJ. Edn 6th Lippincott Williams and Wilkins, Philadelphia; 2001.p.54-79.

7. Sugunnabai NS, Vijayalekshmi MS, Nair PM. Congenital Malformations of the Cardiovascular system. Indian Pediatr 1988;25:839-844.

8. Lurie, IW. Glossary of Malformation Syndromes. In: Ferencz C, Loffredo CA, Correa-Villasenor, Wilson PD. Genetic and Environmental Risk Factors of Major Cardiovascular Malformations, The Baltimore-Washington Infant Study, (1981-1989), Perspectives in Pediatric Cardiology, vol.5. Armonk, N.Y: Futura Publishing Co.Inc,1997; pp. 396-403.

9. Campbell M. Causes of Malformations of the heart. Br Med J 1965;2:825-830.

10. American heart Association 2006. Smoking in Pregnancy Causes Congenital Heart Defects web site:http://www.medscape.com/viewarticle/548088.

11. Begić H, Tahirović HF, Dinarević S, Ferković V, Pranjić N. Risk factors for the development of Congenital heart defects in children born in the Tuzla Canton. Med Arh 2002;56(2):73-7.

12. Muller JHD, Nevin HC. Congenital Malformations and anticonvulsant drugs. Lancet 1973;1:328-329.

13. Wren C, Birrell G, Hawthorne G. Cardiovascular malformations in infants of diabetic mothers. Heart 2003;89:1217-1220.

14. Van Karnebeek CD, Hennekam RC. Associations between chromosomal anomalies and congenital heart defects. Am J Med Genet 1999;84:158-166. 